\title{
LITERATURA E PSICANÁLISE: REPENSANDO A INTERDISCIPLINARIDADE
}

\section{Ana Maria Clark Peres}

$U F M G$

\begin{abstract}
A psicanálise aplicada a obras de arte, literárias, plásticas, como também a acontecimentos históricos e, cada vez mais, a fatos e gestos, às cidades e aos campos, aos animais e às pessoas, dá freqüentemente uma impressão de gratuidade na interpretação, acompanhada por uma certeza de identificação. Instala-se diante da obra e descobre-se um autor atrás, acima, abaixo, ao lado dela. Busca-se, busca-se e acredita-se ter achado.
\end{abstract}

François Regnault

\section{RESUMO:}

Este ensaio tem como objetivo repensar questões relativas à interdisciplinaridade, buscando compreender a interlocução Literatura/Psicanálise enquanto vivência de experiências, ou seja, a partir de uma implicação radical no processo analítico e na leitura de um texto literário. PALAVRASCHAVE:

Interdisciplinaridade, Psicanálise, Criação Literária, Leitura.

\section{O comparativismo e a interdisciplinaridade - uma interlocução} com a Psicanálise

Dentre as variadas possibilidades de pesquisa que os estudos de Literatura Comparada nos oferecem atualmente, é meu desejo repensar neste momento questões relativas à interdisciplinaridade, ou seja, compreender o comparativismo - ou uma faceta dele - enquanto cotejamento de áreas 


\section{LITERATURA E PSICANÁLISE: REPENSANDO A INTERDISCIPLINARIDADE}

Ana Maria Clark Peres

UFMG

A psicanálise aplicada a obras de arte, literárias, plásticas, como também a acontecimentos históricos e, cada vez mais, a fatos e gestos, às cidades e aos campos, aos animais e às pessoas, dá freqüentemente uma impressão de gratuidade na interpretação, acompanhada por uma certeza de identificação. Instala-se diante da obra e descobre-se um autor atrás, acima, abaixo, ao lado dela. Busca-se, busca-se e acredita-se ter achado.

François Regnault

\section{RESUMO:}

Este ensaio tem como objetivo repensar questões relativas à interdisciplinaridade, buscando compreender a interlocução Literatura/Psicanálise enquanto vivência de experiências, ou seja, a partir de uma implicação radical no processo analítico e na leitura de um texto literário. PALAVRASCHAVE:

Interdisciplinaridade, Psicanálise, Criação Literária,

Leitura.

\section{com a Psicanálise}

O comparativismo e a interdisciplinaridade - uma interlocução

Dentre as variadas possibilidades de pesquisa que os estudos de Literatura Comparada nos oferecem atualmente, é meu desejo repensar neste momento questões relativas à interdisciplinaridade, ou seja, compreender o comparativismo - ou uma faceta dele - enquanto cotejamento de áreas 
distintas, que se confrontam e interagem em nível teórico e sobretudo na prática de nossas investigações.

De que maneira "compararíamos", pois, Literatura e Psicanálise?

Trata-se de um tema já amplamente discutido e mesmo insistentemente trabalhado em inúmeros projetos. Interessa-me, contudo, focalizá-lo uma vez mais, justamente pelos tantos enganos (ou até abusos) que, a meu ver, persistem em publicações referentes ao assunto.

Se para muitos parece inquestionável, hoje, a inadequação de uma Psicanálise "aplicada" a textos literários, esse tipo de enfoque continua prevalecendo em estudos diversos e largamente difundidos, que nos apresentam abordagens críticas pretensamente de "inspiração psicanalítica".

Como exemplo, lembraria inicialmente o (ainda) tão comentado Psicanálise dos contos de fadas, de Bruno Bettelheim, em que o autor se utiliza de conceitos freudianos para difundir uma pedagogia libertária da criança, através dos clássicos contos de fadas, contrariando radicalmente pressupostos teóricos e a prática de Freud. Em outro nível, salientaria igualmente trabalhos como o de Patrick Mahony, Sobre a definição do discurso de Freud, no qual, a pretexto de levar a cabo uma análise estilística da escrita freudiana, o psicanalista e professor de literatura inglesa dispõe-se a "explicar" o próprio Freud, em sua crítica-divã. Em análises deste gênero, o que acaba por se destacar é a figura de um autor anterior ao texto produzido, texto esse que não passaria de um reflexo de sua personalidade, de seus afetos ou de seu mundo interior.

Mesmo quando não ocorrem tais fatos, penso que muitas vezes o uso de um instrumental psicanalítico consiste tão somente numa tendência da crítica em determinado momento (quando não de um puro modismo), prestes a ser substituída por outra, mais "em voga", atitude desprovida, assim, de maiores implicações do crítico em sua prática.

Sem negligenciar as variadas tendências da crítica através dos tempos, as quais marcam o percurso dos estudos literários, é meu intento repensar a interlocução Literatura/Psicanálise enquanto vivência de experiências, ou, em outros termos, a partir de uma implicação radical no processo analítico e na leitura de um texto literário.

\section{O diálogo inaugural de Freud}

A interlocução com a Literatura remonta ao nascimento da Psicanálise, que é inventada por Freud com o estímulo de textos literários, que desempenhavam, ao que tudo indica, um papel de destaque em sua vida e em suas pesquisas. Como ele próprio ressalta em $A$ interpretação dos sonhos, foi um texto de Goethe - "Natureza" — que despertou seu interesse pelo estudo das Ciências Naturais. Da mesma forma, uma obra literária levou-o ao conceito básico de sua teoria, o complexo de Édipo: "A Antigüidade nos deixou (...) uma lenda, cujo sucesso completo e universal só pode ser compreendido se se admite a existência de tendências semelhantes na alma da criança. Eu falo da lenda de Édipo-Rei e do drama de S6focles".

Se os modernos se sentem tão tocados por essa peça quanto os contemporâneos de Sófocles, isso se deve, segundo Freud, não ao contraste entre o destino e a vontade humana, mas à natureza do material que serve para ilustrar esse contraste:

O destino de Édipo nos comove porque ele poderia ser o nosso, porque, no momento de nosso nascimento, o oráculo pronunciou contra nós essa mesma maldição (...). O poeta, revelando a falta de Édipo, nos obriga a olhar em nós mesmos e a reconhecer aí esses impulsos que, mesmo reprimidos, existem sempre (...). Como Édipo, nós vivemos inconscientemente desejos que ferem a moral e que nos são impostos pela natureza. ${ }^{2}$

Não se trata, a meu ver, como se diz comumente, de uma simples utilização por parte de Freud de um exemplo (ou conteúdo) extraído de uma obra literária para montar e/ou ilustrar sua teoria. Exatamente porque a Literatura o provocava sempre, e nela os grandes dramas da humanidade se encenam e se revelam sem cessar, ele inicia essa primeira interlocução, confirmada, aliás, por vários de seus estudos. Além de Sófocles e de Goethe, referência constante em sua obra, outros autores são insstentemente lembrados: Shakespeare, Dostoïevski, Ibsen, Maupassant, irmãos Grimm, etc. As conexões entre a escrita poética e a escrita onírica constituem, da mesma forma, questão de destaque, assim como inúmeros ensaios focalizando obras literárias (Gradiva, de Jensen; um conto de Hoffmn, "O homem da areia"), personagens (Hamlet), artistas plásticos (Leonardo da Vinci, Michelangelo), entre outros.

Desses trabalhos, destaco "O criador literário e a fantasia", apresentado

1. FREUD, 19870. p.227-228. (Iroduşäo minho.)

2. Ibidem, p.229. 
originalmente a um público de Letras, em dezembro de 1907, ocasião em que Freud busca salientar o processo criador da Literatura, a partir da brincadeira (encenação) infantil. Trazendo para o primeiro plano os mecanismos de construção do texto poético e/ou ficccional, ele declara: "cada criança que brinca se comporta como um poeta, na medida em que cria um mundo novo, ou melhor, reorganiza os elementos de seu mundo segundo uma ordem nova, da maneira que lhe convém"3.

Mesmo com relação à formação do psicanalista, considerava fundamentais os estudos literários, como se observa no trecho a seguir:

Se, o que hoje ainda pode parece fantástico, fosse fundada uma escola superior de psicanálise, seria necessário ensinar nessa instituição muitas coisas que se ensinam na Faculdade de Medicina (...). Por outro lado, o ensino analítico englobaria também especialidades que são estranhas ao médico e que ele não encontra em sua atividade profissional: história da civilização, mitologia, psicologia das religiões e literatura. ${ }^{4}$

Quanto a Lacan, em seu retorno a Freud, é igualmente constante o diálogo com a Literatura, o qual se manifesta em diversos ensaios: "Lituraterra"; estudo sobre a Carta roubada, de Poe; sete lições sobre Hamlet; análises de Booz adormecido, de V. Hugo; do Balcão, de Genet; de Antígona é Édipo em Colona, de Sófocles; da trilogia de Claudel ( $O$ refém, O pão-duro, O pai humilhado); seminários sobre Joyce; trabalhos sobre o Misantropo, de Molière; "Homenagem a Marguerite Duras", "Mocidade de Gide", entre outros.

Se a Psicanálise inaugura essa interlocução, constituindo-se, insisto, a partir daí, de que maneira nós, da área de Letras, poderíamos hoje manter esse diálogo, sem cair nas “análises aplicadas”?

Uma resposta a essa indagação é o que pretendo desenvolver nos itens que se seguem.

Cotejando experiências distintas: o tratamento analítico e a construção/ leitura de um texto literário.

Como ponto de partida de minhas reflexões, destaco a afirmação de Lacan em "Mocidade de Gide", texto que faz parte de seus Escritos:

3. FREUD, 19850, p.212. (Traduçōo minho.)

4. FREUD, 1985b. p. 133. (Troduçáo minho.)
A psicanálise só se aplica, no sentido próprio, como tratamento e, portanto, a um sujeito que fala e que ouve. Fora desse caso, só pode tratar-se de método psicanalítico, aquele que procede ao deciframento dos significantes, sem considerar nenhuma forma de existência pressuposta do significado. ${ }^{5}$

Mas de que forma nos apropriaríamos de um "método psicanalítico"? Lançando mão tão somente de conceitos retirados de obras teóricas de Psicanálise, para "jogá-los" na Literatura?

Não se trata disso, creio eu, e é justamente este o ponto que desejo discutir: seria possível apreender a teoria psicanalítica e proceder ao deciframento de significantes de um texto literário, sem a vivência dos conceitos a serem trabalhados? Ou melhor dizendo: seria possível a apreensão dessa teoria sem uma prática de análise?

O próprio Freud introduz essa discussão, nos primórdios da Psicanálise. No que se refere à formação do analista, enfatiza repetidamente a importância de este ter contato com a nova área de estudos a partir de uma experiência concreta de análise. Em "Análise com fim e análise sem fim", por exemplo, indica que só a análise pessoal poderá dar ao psicanalista a preparação adequada à sua atividade. Em "A propósito da psicanálise dita selvagem", insiste nessa idéia, ressaltando não ser possível aprender a técnica psicanalítica nos livros. Já no texto "A questão da análise profana", estende a afirmação (e é o ponto que eu gostaria de enfatizar) aos não-analistas interessados em trabalhar com o método psicanalítico:

Se os representantes das diversa ciências do espírito (...) querem aprender a psicanálise (...), não basta levar em conta apenas os resultados consignados na literatura analítica. É necessário que aprendam a psicanálise pela única via que lhes é oferecida, ou seja, submetendo-se eles mesmos a uma análise. ${ }^{6}$

Mas quanto o cotejamento de experiências proposto (tratamento analítico versus criação/re-criação da Literatura)?

É ainda Freud quem introduz esse confronto, ao se referir à peça de
5. LACAN, 1966. p. 747-748. (Troduşüo minho.)

6. FREUD, 1985b, p. 137. 
Sofocles: "A peça nada mais é que uma revelação progressiva e hábil comparável à uma análise - do fato de que o próprio Édipo é o assassino de Laio, mas também o filho da vítima e de Jocasta".

Em outros termos, nessa peça uma verdade se anuncia progressiva $e$ habilmente, e o próprio Freud se encarrega de sublinhar: o processo é "comparável à uma análise".

É este o tipo de interlocução (ou de comparação) que me interessa realizar: focalizar a Literatura, confrontando-a - a sua criação e sobretudo a sua leitura - com o desenrolar de um tratamento analítico.

O mesmo procedimento é retomado por Julia Kristeva, quase um século mais tarde, em Jornada de Psicanálise (janeiro de 1989, em Paris). Ao generalizar os estudos de Freud sobre o Édipo, ela menciona o caráter universal de toda análise (as leis gerais do aparelho psíquico), ressaltando, contudo, a particularidade de uma experiência analítica: "cada tratamento [chaque cure] é uma obra de arte".

Para a abordagem de vivências tão complexas, um recorte se faz necessário, com o enfoque de alguns tópicos comuns a essas experiências.

\section{(encenação)}

\section{A implicação no processo - os vários níveis de atualização}

[O leitor] joga com o Texto (sentido lúdico), busca uma prática que o re-produza; mas para que essa prática não se reduza a uma mimesis passiva, interior (o Texto é justamente aquilo que resiste a essa redução), ele joga o jogo de representar o Texto; não se pode esquecer que jouer (além de ter um sentido lúdico: jogar, brincar) tem um sentido cênico: representar..

\section{Roland Barthes}

Se se coteja um tratamento analítico com a criação ou leitura de um texto literário, algo se anuncia de imediato, indispensável a essas realizações: a implicação no processo.

7. FREUD, 19870. p.228
Ora, já é por demais sabido que não se leva a cabo uma análise sem a dinâmica de uma transferência, concebida, antes de mais nada, como atualização de afetos passados, ou, segundo Lacan, como a "posta em ato [mise-en-acte] da realidade do inconsciente". Em tal processo não se volta ao passado, mas é este que vem até nós, atualizando-se no percurso de um tratamento. Como lembra Freud, através da transferência o analisante se permite expor um fragmento importante de sua história, reproduzindo-o de maneira presente, em vez de simplesmente recordá-lo. Trata-se, portanto, de uma encenação involuntária, que provoca a implicação na experiência analítica, viabilizando o seu desenrolar. No dizer de Nasio, a análise é justamente aquele "fragmento de vida composto de múltiplos fragmentos de vida"".

E quanto ao texto literário?

No que diz respeito à sua leitura, talvez tenha sido Barthes quem melhor anunciou essa implicação-encenação, ao apontar o jogo de cada leitor com o texto que o provoca. À procura de uma prática que o re-produza, ele atualiza os fragmentos de sua própria vida naquele recorte que lhe é oferecido: "O Texto, apenas o Texto, dizem-nos, mas apenas o texto, isso não existe; há imediatamente nesta novela, neste poema que estou lendo, um suplemento de sentido de que nem a gramática nem o dicionário podem dar conta"10. Um $a$ mais que é do próprio sujeito-leitor, implicado em seu processo de leitura, processo este entendido como resultado de um investimento transferencial do leitor com o texto que o seduz. Afinal, como afirma Barthes no mesmo artigo, "ler é fazer trabalhar o nosso corpo ao apelo dos signos do texto""l. Concebido dessa forma, $o$ ato de ler se constituiria numa produção significante (produção de significantes), se se considera que, na leitura, o sujeito se representa, via Literatura.

Mas se o texto literário propicia essa implicação dos leitores, isso se deve ao fato de ele mesmo já ser uma atualização: a articulação (encenação) de variados fragmentos de vida, num complexo jogo intertextual. ${ }^{12}$

Nessa nova perspectiva, a "velha" questão das influências pode ser

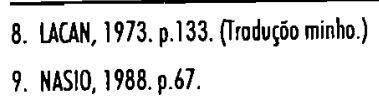
e com sev inconsciente". (BARTHES, 1982. p. 191.)

12. Como nos indico aindo Borthes, no Avia, o Literaturo "enceno a linguogem em vez de, simplesmente, utilizó-lo...." (BARTHES, 1979. p. 19.) 
diferentemente enfocada, uma vez que não se trata mais de ir atrás de origens diversas, de um retorno às fontes, numa volta ao passado, mas sim de verificar como essas fontes retornam, no escritor e no leitor: retorno a nós, em nós, de um dizer e de uma experiência. Importa verificar, enfim, como os fragmentos da série literária e/ou de outras séries se articulam e se encenam no presente, para revelar uma verdade do (no) escritor, a qual irá jogar com a verdade do (no) leitor.

Tal movimento é distinto, por exemplo, do que propõe Bloom, em The anxiety of influence. Procurando rever o sistema das filiações, ele assinala seis tipos de procedimento: correção dissidente; acabamento; ruptura; abertura; auto-purgação; retorno ao ponto de origem. Mesmo valorizando o novo rumo tomado pelo texto do presente, suas explicações, a meu ver, acabam por enfatizar as origens da produção atual, numa interpretação psicologizante da Literatura.

Diferentemente, é o percurso das atualizações, tanto num tratamento analítico quanto na construção ou leitura de um texto literário, que passo a focalizar nos tópicos que se seguem.

\section{Bordejando o Real}

Não creio que a literatura seja uma questão de temas. Meus relatos contam (...) sempre o mesmo, mas não saberia dizer de que se trata. Existiria então uma constante. Nesse caso não seria temática, mas técnica: eu procuro construir meus relatos a partir do não dito, de certo silêncio que deve estar no texto e sustentar a tensão da intriga. Não se trata de um enigma (ainda que possa tomar essa forma), mas de algo mais essencial: a literatura trabalha com os limites da linguagem.

\section{Ricardo Piglia}

Como indica Nasio, uma análise pode ser compreendida como uma montagem que se constrói pouco a pouco em torno do furo. Ao aceitar a condução de um tratamento, o analista se empenha, assim, em construir junto com o analisante uma realidade própria em torno de uma falta. Com relação à arte, Lacan explicita igualmente esse furo, ao propor que cada obra "se caracteriza por um certo modo de organização em torno [do] vazio". ${ }^{3}$

Percebe-se, pois, que a falta é determinante em ambos os processos. Algo não se apreende completamente, e a escrita nada mais faz que bordejar essa falta. E é justamente porque há esse Real em jogo, impossível de ser representado - o que não cessa de não se escrever —, que somos impulsionados a um movimento constante de escrita, ou de re-escrita, via leitura. (Vale ressaltar que uma análise também se "escreve" ou se "re-escreve", a partir de um já escrito.) Não fazendo parte de um tratamento, é o Real, no entanto, a razão de tudo o que aí ocorre. Dele, aponta Nasio, o analista permanece excluído, o que não deixa de ser uma forma de relação:

A originalidade da teoria lacaniana não foi a de acentuar que há um lugar no qual somos estrangeiros, mas a de dar a escutar que (...) a essência do homem consiste em manter viva (...) a relação com aquilo que não somos (...), e que essa relação é precisamente o desejo (...). Passamos nosso tempo a colocar aí dizeres, artifícios, mitos e - por que não? - teorias, pseudo problemas, às vezes metafísicos. Ora, tudo o que se planta nessa terra de exílio não consegue significá-la. Nenhuma abordagem (...) deste lugar de exclusão poderia abolir sua exclusão.."

Chegar ao verdadeiro, numa análise, prossegue Nasio, é chegar a um dizer que muda o sujeito e que sobretudo desperta o Real, indicando-o como causa de nossas ocorrências.

\section{E com relação à Literatura e suas conexões com o Real?}

Como Barthes, na Aula, assinalariamos que é precisamente porque o Real não se representa, e porque os homens insistem em querer representá-lo, que há Literatura e seus intermináveis "expedientes", que não cessam de demonstrar esse desacerto fundamental, esse impossível desejo. Um impossível, causa do próprio desejo, e seu limite. A mesmice do Real (o que volta incessantemente ao mesmo lugar) provocando toda análise e toda criação literária. Desse ponto de vista talvez seja possível entender a colocação de Piglia de que seus textos contam sempre o mesmo: "a literatura trabalha com os limites da linguagem"'s. Mesmice capaz de desencadear, então, uma "constante técnica",

13. LACAN, 1986. p.155. (Traduçāo minha.)

14. NASIO, 1988. p.64-65.

15. PIGLA, 1990. p. 105. (Traduç̧̄o minho.) 
obstinada re-petição: no quadro da demanda o desejo se expressando.

Quanto à leitura, o processo persiste, a meu ver. Exatamente porque nunca se lê tudo - não se apreende o significado último e definitivo de um texto -, lê-se outra vez: o mesmo ou um novo texto.

Enfocado o "mesmo", interessa-me agora o incessantemente "outro". Cada análise e cada texto apreendidos em sua diferença: insistências (expedientes) infinitamente renovados, reinventados, sustentando outras (novas) montagens - em torno do vazio.

\section{multiforme}

\section{Um recorte fundamental: o fantasma e suas repetições}

A diferença do Texto (...) não é o que designa a individualidade de cada texto, o que o nomeia, autentica (...), termina; é, pelo contrário, uma diferença que não pára e se articula no infinito dos textos, das linguagens, dos sistemas: uma diferença que se repete em cada texto.

\section{Roland Barthes}

Numa análise, a repetição constitui mecanismo fundamental. Segundo Freud, deixar que as repetições se efetuem é evocar um fragmento de vida real evocação, aliás, que não pode ser considerada inofensiva, sem riscos, sendo um desses riscos precisamente o fantasma.

Escrita minimal que sustenta cada uma de nossas produções, permitindo-nos suportar o Real e tecer a trama da realidade, o fantasma, no tratamento analítico, é tenaz. Como ressalta Gantheret, nós o encontramos em sua repetição multiforme, ao longo de toda a análise, "hábil em simular seu desaparecimento e sempre novamente reencontrado"16. Compreendido como a maneira com que o sujeito lida com a falta no Outro, implicando-se com o objeto do desejo e, portanto, com a própria falta, todas as suas definições incidem sobre sua característica mais marcante: a de encenar o Real. "Memória de um paraíso que jamais existiu”, "máscara”, "simulacro", "montagem fundamental”,

16. GANTHERET, 1986. p.88 ('Traduş̧óo minho.) é por sua via que o sujeito busca atingir o gozo absoluto, através de um artifício peculiar: coloca-se na posição de objeto do desejo do Outro, enquanto o Outro desejante se reduz igualmente a objeto desejado.

Em virtude dessa busca incansável de um gozo pleno é que o fantasma nem sempre se apresenta da mesma maneira:

Em alguns momentos certas cenas prevalecem; mais tarde um outro cenário se impõe; o seu objetivo sem dúvida é fixo, mas vários cenários diferentes procuram alcançá-lo. Cada vez que um desses cenários encontra o impossível, [o fantasma atualiza] uma nova versão da mesma busca de gozo."

Se uma análise não chega ao fim sem a sua construção (e travessia), $e$ possível situá-lo igualmente no princípio da criação artística e, por conseguinte, literária, na medida em que coloca em jogo o mais íntimo de cada autor. Paradigma que revela a verdade do sujeito, matriz de todos os nossos atos, é a sua insistência significante que me interessa focalizar no texto literário. Como indica Lacan, a verdade não consiste em idéias, nem no significado, senão que insiste nelas. $^{18}$

É importante esclarecer neste ponto o conceito de "verdade" que procuro enfatizar no meu trabalho. Trata-se, em última instância, da verdade (lógica) do fantasma fundamental. Se este pode ser entendido como um axioma ${ }^{19}$, e se axioma em Lógica é uma proposição assumida como verdadeira, "para deduzir conseqüências igualmente particulares, verdadeira unicamente sob esta condição"20, percebe-se que o sentido de verdade aqui destacado é bem específico. Não se trata certamente de uma verdade coletiva irrefutável, transcendente, mas sim de uma verdade particular, suposta, assumida enquanto tal. Para deduzir conseqüências particulares, ela própria se constitui como efeito de uma construção a posteriori, provocada pela efetuação do encadeamento dedutivo. Não consiste, pois, numa verdade factual, comprovável, mas numa ficção, a indicar, repito, aquilo que de mais íntimo há no sujeito, seja em relação a seu gozo ou a seu desejo.

17. POMMIER, 1990. p.8.

18. 0 oprofundomento desse tópicoé tema de minho tese de Doutorado - O infontil na literatura: umo questão de estila ; defendido em abril de 1995 no Foculdade de Letros do UFMG.

19. (f. LACAN, Seminório (inédito) logique du fontosme, 1966-67.

20. GRANGER, 1955. p.227. 
Insistindo na cadeia significante - tanto num tratamento analítico quanto num texto literário - , apresentando-se a cada momento idêntica e sempre nova, através das mais diferentes construções fantasmáticas, tal verdade não pode nunca ser completamente lida, atingida, tampouco confundida com um significado primeiro a ser desvelado, ou com um conteúdo mais profundo. (Lembremos que, para Lacan, não há sujeito das profundezas, mas sujeito pontual e evanescente.)

\section{Uma escrita contextualizada}

Mais adiante você fala em "apertado dilema: nacionalismo ou universalismo. O nacionalismo convém às massas, o universalismo convém às elites”. Tudo errado. Primeiro: não existe essa oposição entre nacionalismo e universalismo. O Brasil pros brasileiros - ou regionalismo exótico. Nacionalismo quer simplesmente dizer: ser nacional. $O$ que mais simplesmente ainda significa: ser. Ninguém que seja verdadeiramente, isto é, viva, se relacione com o seu passado, com as suas necessidades imediatas, práticas e espirituais, se relacione com o meio e com a terra, com a família, etc; ninguém que seja verdadeiramente deixará de ser nacional.

\section{Mário de Andrade}

Ao se perseguir, no texto literário, o movimento das repetições multiformes que apontam para uma insistência significante, o que acaba por se desvelar são os vários níveis de encenação, ou seja, a inserção de um texto em determinado contexto que, por sua vez, jogará com o contexto do leitor, que reescreve esse fragmento de vida em sua leitura crítica. $O$ mesmo procedimento ocorre no tratamento analítico, que se desenvolve a partir das vinculações do sujeito com o seu meio, com a história de seu tempo e com a sua história pessoal. A diferença se fazendo, pois, através da contextualização, ao se tomar cada caso em sua singularidade.

Um bom exemplo dessa inserção pode ser encontrado no trabalho do sonho, de cuja interpretação se vale sem cessar uma análise. Ora, o próprio Freud ressaltou várias vezes que a escrita onírica só se torna passível de deciframento se se considera um contexto específico, o que significa que todo material que constitui seu conteúdo manifesto provém, de uma maneira ou de outra, de uma experiência vivida - cenas infantis, sexuais, restos diurnos que é reproduzida ou rememorada no sonho. Tal processo se repete, sem dúvida, com relação a qualquer material que é elaborado no desenrolar de um tratamento: ao atualizar fatos passados, o que o analisante faz nada mais é do que jogar com contextos diversos, nos quais se implica na atualidade e/ou se implicou no passado.

Mesmo no que concerne à Literatura, essa idéia sempre esteve presente nos trabalhos de Freud. Ao comparar, por exemplo, Édipo e Hamlet, ele assinala: "A realização completamente distinta de uma matéria idêntica mostra que diferenças existem na vida intelectual dessas duas épocas, e que progresso o recalcamento fez na vida afetiva da humanidade". ${ }^{21}$

Conclui-se, dessa forma, que trabalhar a Literatura em interlocução com a Psicanálise, resgatando pressupostos básicos da descoberta freudiana, seria lidar, antes de mais nada, com escritas contextualizadas, que denunciam incessantemente a implicação do sujeito com a sua história, ou, mais radicalmente, com escritas que só ganham sentido via contextualização.

Nessa via - ou Estilo - por onde "a verdade mais escondida se manifesta nas revoluções da cultura" ${ }^{\text {"2l }}$. Verdade-ficção que se apresenta enquanto "verdade histórica" do sujeito, ou, em outros termos, como o infantil que se atualiza e se reinventa sem cessar. ${ }^{23}$

\section{RÉSUMÉ:}

Le but de cet essai est de repenser des questions qui concernent l'interdisciplinarité, en cherchant à comprendre l'interlocution Littérature/Psychanalyse comme un dialogue d'expériences vécues, c'est-à-dire, en partant d'une implication radicale dans le processus analytique et dans la lecture d'un texte littéraire. MOTS-ClES:

Interdisciplinarité, Psychanalyse, Création Littéraire, Lecture.

21. FREUD, 19870. p.230.

22. LACAN, 1966. P. 458

23. Desse conceito ("verdade histórico", que revelo a história pessoal do sujeito) se ocupou Freud sobretudo no final de suo vido. Um texto especticomente, "Constructions dans l'anolyse" (FREUD, 1987c. p.279-281) ilustro, com ênfase, a questöo 


\section{ANTROPOLOGIA E HISTÓRIA NA INTERLOCUÇÃO ENTRE 0 FEMININO E A LITERATURA'}

REFERÊNCAS BIBLIOGRÁFICAS

ANDRADE, Mário de. A liço do omigo : cantas de Mário de Andrade, anotodas pelo destinatorio. Rio de Janeiro: J. Olympio, 1982. BARTHES, Rolond. Aulo. Trad. Leylo Perrone-Moisés. Sãa Poulo: Cultrix, 1979.

Escrever a leitura. In: _. O numar da Ifrnguo. Trod. Mario Loranjeirro. Säo Paulo: Brosiliense, 1984. p.40-42

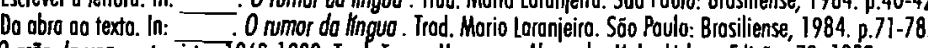

g grũo do voz : entrevistos 1962-1980. Irod. Tereso Meneses e Alexondre Melo. Lisboo: Ediçôes 70, 1982.

- S/2. Irad. Morio de Sonto Cruz e Ano Mafalda Leite. Lisboo: Ediçées 70, 1970.

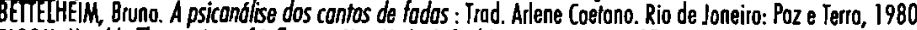

BlooM, Harold. The onxiely of infuence. Hew York: Oxdord University Press, 1973 .

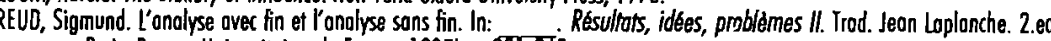
Paris: Presses Universitaires de Fronce, 1987b. p.231-26B.

Constructions dons l'anolyse. In: Rn: Résultats, idées, probiemesll. Trod. Jeon Loplonche. 2.ed. Paris: Presses Universitaires de France, 1987c. p. $269-281$.

Lo créateur litteraire et lo fontaisie. In: L'inquiérante éfrangete, et outres essais. Irod. Bertrond Féron. Paris

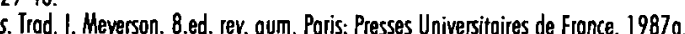

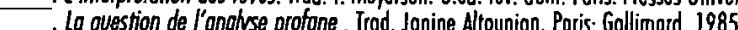

_. A propos de lo psychanalyse dite souvage. In: . Lo technique psychonalytique. Trod. Anne Bermon. 8. ed. Paris. Presses Universitoires de Fronce, 1985C. p.35-42.

GANTHERET, Froncois. L'incertitude d'eros. Paris: Gollimord, 1986

GRANGER, Gilles Goston. Loggico e filosofio das cienncios. Sõo Paulo: Melhoramentos, 1955.

LACAN, Jocques. Jeunesse de Gide ou la letrire ef le désir. In: Gerits. Paris: Seuil, 1966.

Logique du fontosme, séminaire 1966-67. [s.n.t.]. 27. (Inédito).
Lo psychonalyse et son enseignement. In: Ecits. Paris: Sevil, 1966. 0.437-458

Le séminaire livre VII: L'éthique de lo psychanolyse. Paris: Sevil, 1986.

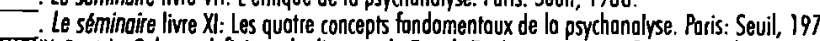

NASIO, Juan David. A crianco mognffica do psiconálise : o conceita de sujeito e objeto no teoria de Jacques Locan. Trad. Duke Duque Estroda Ria de Joneira: Jorge Zohor, 1988 .

PERES, Ano Moria Cark, O infontil no literatura: uma questöo de estilo. Belo Horizonte: Faculdode de Letros da UFMG, 1995. (Tese, Doutoroda em Literotura Comporoda.)

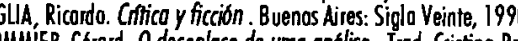

. Cistino Rollo de Abreu. Rio de Janeiro: Jorne Zohor, 1990

REGNAULIT, Froncois. Essos esquisititices obundontes nos textos psicanolíiticos. In: MIlLER, Gérard (Org.). Locon. Irod. Luiz Forbes. Rio de Joneiro, Jorge Zahor, 1989.
Haydée Ribeiro Coelho

$U F M G$

RESUMO:

Esse trabalho tem como objetivo enfocar a crítica do ferninino pela Antropologia e pela História, para evidenciar o diálogo entre o discurso teórico contemporâneo dessas disciplinas e a representação da mulher na literatura. PALAVRASCHAVE:

Crítica, Feminino, Antropologia, História.

A idéia desse estudo originou-se de uma disciplina, ministrada por mim e por Angela Freitas Senra aos alunos da Pós-Graduação (FALE - UFMG), no primeiro semestre de 1995, intitulada Literatura, História e Antropologia. Nesse curso, a memória teceu o fio que permitiu a interlocução entre os vários discursos. Particularmente, no enfoque entre a Literatura e a Antropologia, privilegiei o tema da viagem e da memória, com base em Tristes trópicos de Lévi Strauss, abordado tanto como texto antropológico quanto como literário. A professora Angela Senra destacou a ego-história "como tomada de consciência de que a história que cada um faz é tributária de sua própria história e da relação que teve com sua época"'.

$\mathrm{O}$ interesse pela Antropologia e pela História e a afinidade existente

1. Esse trobalho foi opresentodo originolmente no XI Encontro Nocional do ANPOLL, em 03-06-96, na GT A mulher no Literoturo. 2. CF. MOREIRA LETEE, 1994.

REVISTA DE ESTUDOS DE LITERATURA Belo Horizonte, v. 4, p. $199-209$, out. 96

(1) 89 